\title{
TRANSVERSE VIBRATION OF ORTHOTROPIC RECTANGULAR PLATES UNDER MOVING BODIES
}

\author{
Nguyen Van Khang, Nguyen Minh Phuong \\ Hanoi University of Technology
}

\begin{abstract}
The use of orthotropic plates is common in all the fields of structural engineering: civil, traffic, aerospace and naval. In this paper the transverse vibration of orthotropic rectangular plates under moving bodies is investigated. The method of substructures is used to derive transverse vibration equations of an orthotropic rectangular plate under the action of moving bodies. For the calculation of dynamic response of orthotropic rectangular plate we use Ritz method and numerical integration method.
\end{abstract}

\section{INTRODUCTION}

An orthotropic plate is defined as one, which has different elastic properties in two orthogonal directions. Many types of bridges, such as solid or voided slab decks and beam and slab decks, can be modeled as orthotropic plates. The evaluation of structure- borne noise of a highway or railway bridge can also be considered as an orthotropic plate with moving bodies. However, little work on this area has been done probably because of the difficulty and the plethora of factors and uncertainties involved [1, 2, 3, 5, 8, 9].

The calculating eigenfrequencies of orthotropic plates have been studied in $[3,4,5$, 6]. The dynamical analysis of an orthotropic plate under the action of moving forces has attracted in $[7,8,9]$. The method of substructures and the Ritz method have been used for calculating transverse vibrations of a continuous beam on rigid and elastic supports under the action of moving bodies $[10,11,12]$. In this work, we use the method of substructures to derive transverse vibration equations of an orthotropic rectangular plate under the action of moving bodies. The Ritz method is used to analyze the obtained vibration equations.

\section{DERIVATION OF VIBRATION EQUATIONS USING THE METHOD OF SUBSTRUCTURES}

Consider an orthotropic rectangular plate under moving bodies (Fig. 1). The $i$-th body $(i=1, . ., N)$ consists of the mass $m_{i}$ attached to the spring system with rigidity $k_{i}$ and damping $d_{i}$ directly proportional to the velocity. The $i$-th body moves with the velocity $v_{i}$ and is subjected to the action of a force $G_{i} \sin \left(\Omega_{i}^{*} t+\gamma_{i}\right)$ caused by an unbalanced mass, which rotates with angular velocity $\Omega_{i}^{*}$. Where $G_{i}$ is the amplitude of the force. 


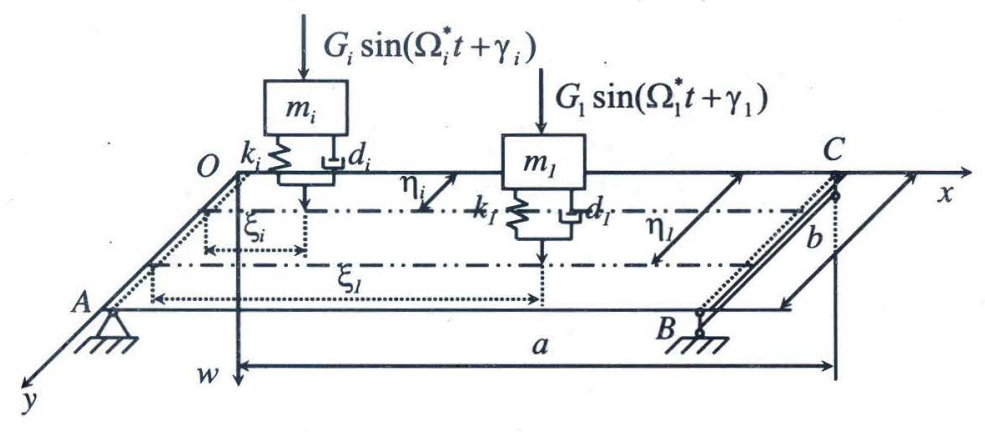

Fig. 1. Vibration model of an orthotropic rectangular plate under moving bodies

Using the method of substructures to derive vibration equations of the plate and the bodies, we divide the system into $N+1$ substructures: plate an $N$ bodies (Fig. 2). In there $z_{i}$ is the absolute coordinate of the $i$-th body in the vertical direction. The position of the $i$-th body can be determined by the relation (1)

$$
\xi_{i}=0 \text { when } t<\tau_{i}, \xi_{i}=v_{i}\left(t-\tau_{i}\right) \text {, when } t \geq \tau_{i}, \eta_{i}=b_{i}=\text { const. }
$$

Where $\tau_{i}$ denotes the time when the $i$-th body starts moving along the straight line $\eta_{i}=b_{i}$ of plate with the constant velocity $v_{i}$. Additionally, it is supposed that during the motion, the $i$-th body is not separated from the plate and its velocity $v_{i}$ satisfies the condition of The pressured load $p(x, y, t)$ of bodies on the plate is determined by the following form:

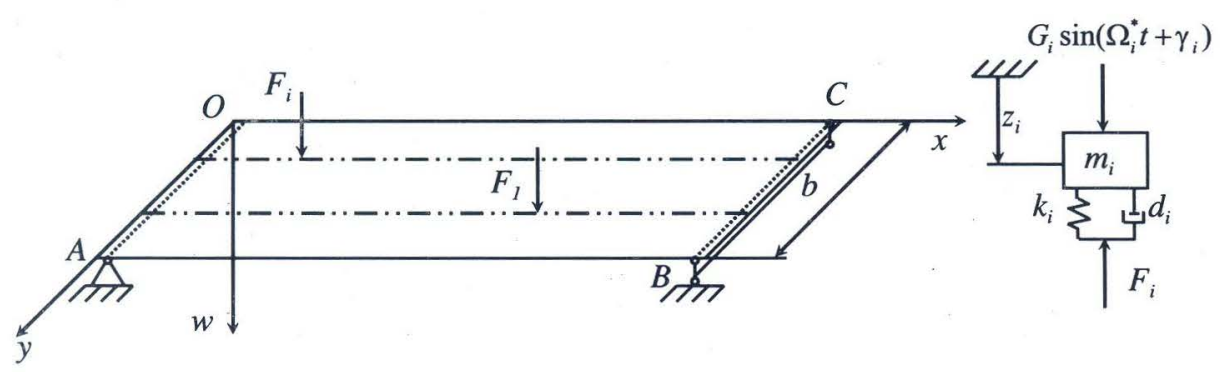

Fig. 2. Substructures

$$
p(x, y, t)=\sum_{i=1}^{N} L_{i}(t)\left[m_{i} g+G_{i} \sin \left(\Omega_{i}^{*} t+\gamma_{i}\right)-m_{i} \ddot{z}_{i}\right] \delta\left(x-\xi_{i}\right) \delta\left(y-\eta_{i}\right) .
$$

In equation (2) we use the Dirac - functions $\delta\left(x-\xi_{i}\right), \delta\left(y-\eta_{i}\right)$ and the logic signal - function $L_{i}(t)$, which are determined by the following relations

with $T_{i}=a / v_{i}$

$$
L_{i}(t)= \begin{cases}1 & \text { when } \tau_{i} \leq t \leq T_{i}+\tau_{i} \\ 0 & \text { when } t<\tau_{i} \text { or } \quad t>T_{i}+\tau_{i}\end{cases}
$$

and $\delta\left(x-x_{0}\right)=\lim _{\varepsilon \rightarrow 0} \delta_{\varepsilon}\left(x-x_{0}\right)$ 
with

$$
\delta_{\varepsilon}\left(x-x_{0}\right)=\left\{\begin{array}{lll}
\frac{1}{2 \varepsilon} & \text { when } & \left|x-x_{0}\right| \leq \varepsilon \\
0 & \text { when } & \left|x-x_{0}\right|>\varepsilon
\end{array} .\right.
$$

An orthotropic material is characterized by the fact that the mechanical elastic properties have two perpendicular planes of symmetry. Due to this condition only four elastic constant are independent, namely $E_{x}, E_{y}, G_{x y}, \nu_{x}$ or $\nu_{y}$. The coefficients $\nu_{x}, \nu_{y}$ can be determined using the equation

$$
\frac{E_{x}}{E_{y}}=\frac{\nu_{x}}{\nu_{y}}
$$

By introducing the parameters

$$
D_{x}=\frac{E_{x} h^{3}}{12\left(1-\nu_{x} \nu_{y}\right)} ; \quad D_{y}=\frac{E_{y} h^{3}}{12\left(1-\nu_{x} \nu_{y}\right)} ; \quad D_{x y}=\frac{G_{x y} h^{3}}{12}
$$

where $E_{x}, E_{y}, \gamma_{x}, \gamma_{y}$ and $G_{x y}$ are material constants of an orthotropic plate and $h$ is the thickness of the plate, and making use of the hypotheses of Lore - Kirchoff, that neglect the effect of the shear forces and the rotational inertia, the equation of the motion of the plate can be written in the form [12]

$$
\begin{aligned}
& D_{x} \frac{\partial^{4} w}{\partial x^{4}}+2 D_{k} \frac{\partial^{4} w}{\partial x^{2} \partial y^{2}}+D_{y} \frac{\partial^{4} w}{\partial y^{4}}+\alpha \frac{\partial}{\partial t}\left[D_{x} \frac{\partial^{4} w}{\partial x^{4}}+2 D_{k} \frac{\partial^{4} w}{\partial x^{2} \partial y^{2}}+D_{y} \frac{\partial^{4} w}{\partial y^{4}}\right] \\
& +\rho h\left(\frac{\partial^{2} w}{\partial t^{2}}+\beta \frac{\partial w}{\partial t}\right)=p(x, y, t),
\end{aligned}
$$

where $\rho$ is the plate density, $w$ is the out-of-plane displacement and

$$
D_{k}=D_{y} \nu_{x}+2 D_{x y} .
$$

If we use the operator $L$ which is defined by

$$
L=D_{x} \frac{\partial^{4}}{\partial x^{4}}+2 D_{k} \frac{\partial^{4}}{\partial x^{2} \partial y^{2}}+D_{y} \frac{\partial^{4}}{\partial y^{4}}
$$

then equation (7) has the following form

$$
L w(x, y, t)+\alpha \frac{\partial L w(x, y, t)}{\partial t}+\rho h\left(\frac{\partial^{2} w}{\partial t^{2}}+\beta \frac{\partial w}{\partial t}\right)=p(x, y, t),
$$

where $\alpha$ and $\beta$ are damping constants.

The equation describing the vibration of the $i$-th body has the following form

$$
L_{i}(t)\left[m_{i} \ddot{z}_{i}+d_{i} \dot{z}_{i}+k_{i} z_{i}\right]=L_{i}(t)\left[m_{i} g+G_{i} \sin \left(\Omega_{i}^{*} t+\gamma_{i}\right)+d_{i} \dot{w}\left(\xi_{i}, \eta_{i}, t\right)+k_{i} w\left(\xi_{i}, \eta_{i}, t\right)\right] .
$$

The boundary conditions can be expressed in the form

$$
\begin{aligned}
& x=0 \quad \text { or } \quad x=a: w=0 \text { and } \quad M_{x}=0 \\
& y=0 \quad \text { or } \quad y=b: M_{y}=0 \quad \text { and } \quad 2 \frac{\partial M_{x y}}{\partial x}+\frac{\partial M_{y}}{\partial y}
\end{aligned}
$$

where $M_{x}, M_{y}$ and $M_{x y}$ are stress couples. 


\section{CALCULATING DYNAMIC RESPONSE BY RITZ METHOD}

Using the mode superposition principle, a solution of equations (7) and (11) with the boundary conditions (12) and (13) is assumed in the form

$$
w(x, y, t)=\sum_{r=1}^{n} \sum_{i=1}^{m} W_{r i}(x, y) q_{r i}(t) .
$$

In which $q_{r i}(t)(r=1, \ldots, n ; i=1, \ldots, m)$ are generalized coordinates to be determined, $W_{r i}(x, y)$ are eigenfunctions.

By substituting the relation (14) into equation (7) we obtain

$$
\sum_{r=1}^{n} \sum_{i=1}^{m} \rho h\left[\ddot{q}_{r i}(t)+\left(\beta+\alpha \omega_{r i}^{2}\right) \dot{q}_{r i}(t)+\omega_{r i}^{2} q_{r i}(t)\right] W_{r i}(x, y)=p(x, y, t) .
$$

Multiplying equation (15) by eigenfunctions $W_{s j}(x, y)(s=1, \ldots, n ; j=1, \ldots, m)$ and then integrating from 0 to $a$ for $x$ and from 0 to $b$ for $y$, and using the orthogonally condition of eigenfunctions we obtain the ordinary differential equations

$$
\ddot{q}_{s j}(t)+\left(\beta+\alpha \omega_{s j}^{2}\right) \dot{q}_{s j}(t)+\omega_{s j}^{2} q_{s j}(t)=\frac{1}{\rho h} f_{s j}(t) ;(s=1, \ldots, n ; j=1, \ldots, m)
$$

in which

$$
f_{s j}(t)=\frac{\iint_{A} p(x, y, t) W_{s j}(x, y) d x d y}{\iint_{A} W_{s j}^{2}(x, y) d x d y} .
$$

From the relation (14) we can calculate the partial derivation

$$
\begin{gathered}
w\left(\xi_{i}, \eta_{i}, t\right)=\sum_{r=1}^{n} \sum_{j=1}^{m} W_{r j}\left(\xi_{i}, \eta_{i}\right) q_{r j}(t), \\
\dot{w}\left(\xi_{i}, \eta_{i}, t\right)=\sum_{r=1}^{n} \sum_{j=1}^{m}\left[W_{r j}\left(\xi_{i}, \eta_{i}\right) \dot{q}_{r j}(t)+\frac{\partial W_{r j}\left(\xi_{i}, \eta_{i}\right)}{\partial \xi_{i}} v_{i}+\frac{\partial W_{r j}\left(\xi_{i}, \eta_{i}\right)}{\partial \eta_{i}} \dot{\eta}_{i}\right] .
\end{gathered}
$$

Substituting the relations (18) and (19) into equation (11) we have

$$
\begin{aligned}
& L_{i}(t)\left[m_{i} \ddot{z}_{i}+d_{i} \dot{z}_{i}+k_{i} z_{i}\right]=L_{i}(t)\left[m_{i} g+G_{i} \sin \left(\Omega_{i}^{*} t+\gamma_{i}\right)\right] \\
& \quad+L_{i}(t) d_{i} \sum_{r=1}^{n} \sum_{j=1}^{m} W_{r j}\left(\xi_{i}, \eta_{i}\right) \dot{q}_{r j}(t) \\
& \quad+L_{i}(t) \sum_{r=1}^{n} \sum_{j=1}^{m}\left[d_{i}\left(\frac{\partial W_{r j}\left(\xi_{i}, \eta_{i}\right)}{\partial \xi_{i}} v_{i}+\frac{\partial W_{r j}\left(\xi_{i}, \eta_{i}\right)}{\partial \eta_{i}} \dot{\eta}_{i}\right)+W_{r j}\left(\xi_{i}, \eta_{i}\right)\right] q_{r j}(t) .
\end{aligned}
$$

If we introduce the new vector

$$
\mathbf{y}(t)=\left[\begin{array}{llllllll}
q_{1}(t) & q_{2}(t) & \ldots & q_{m \times n}(t) & z_{1}(t) & z_{2}(t) & \ldots & z_{N}(t)
\end{array}\right]^{T}
$$

then differential equations (16) and (20) can be written in the following matrix form

$$
\ddot{\mathbf{y}}=\mathbf{B}(t) \dot{\mathbf{y}}+\mathbf{C}(t) \mathbf{y}+\mathbf{f}(t) \text {. }
$$


The Runge - Kutta method is used for calculating the solutions of the ordinary differential equation (21). Based on this algorithm, a computer program for calculating transverse vibrations of orthotropic rectangular plates under moving bodies is created using $\mathrm{C}++$ language at the Hanoi University of Technology.

\section{EXAMPLE}

The Fig. 3 shows the mechanical model of the considered orthotropic rectangular plate

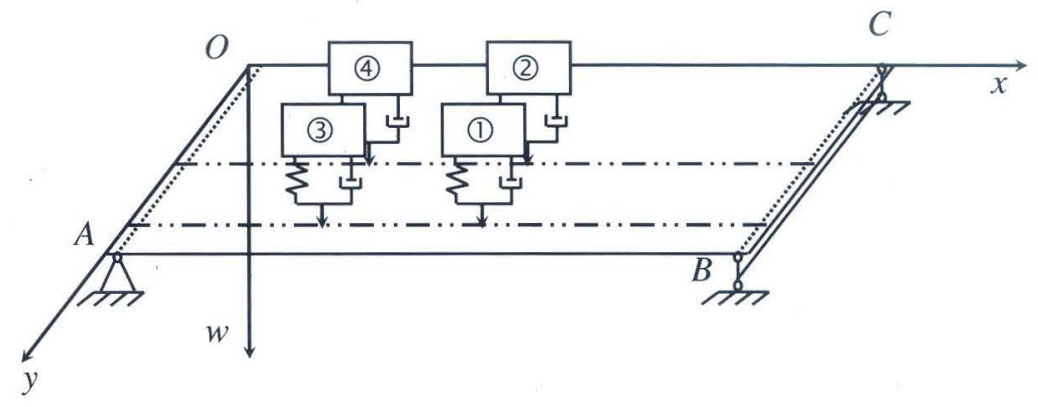

Fig. 3. Model of an orthotropic rectangular plate

Table 1. The data for calculating

\begin{tabular}{|l|l|l|}
\hline$a=20 \mathrm{~m}$ & $m_{1}=2160 \mathrm{~kg}$ & $m_{3}=5040 \mathrm{~kg}$ \\
$b=11 \mathrm{~m}$ & $k_{1}=364500 \mathrm{~N} / \mathrm{m}$ & $k_{3}=850500 \mathrm{~N} / \mathrm{m}$ \\
$h=0.43 \mathrm{~m}$ & $d_{1}=4200 \mathrm{Ns} / \mathrm{m}$ & $d_{3}=9800 \mathrm{Ns} / \mathrm{m}$ \\
$\rho=2300 \mathrm{~kg} / \mathrm{m}^{3}$ & $v_{1}=6.9444 \mathrm{~m} / \mathrm{s}$ & $v_{3}=6.9444 \mathrm{~m} / \mathrm{s}$ \\
$E_{x}=176.295^{*} 10^{9} \mathrm{~N} / \mathrm{m}^{2}$ & $y_{1}=8 \mathrm{~m}$ & $y_{3}=8 \mathrm{~m}$ \\
$E_{y}=2.1 * 10^{9} \mathrm{~N} / \mathrm{m}^{2}$ & $\tau_{1}=0 \mathrm{~s}$ & $\tau_{3}=0.49 \mathrm{~s}$ \\
$G_{x y}=32.542^{*} 10^{8} \mathrm{~N} / \mathrm{m}^{2}$ & $G_{1}=0 \mathrm{~N}$ & $G_{3}=0 \mathrm{~N}$ \\
$\nu_{x}=0.33$ & $m_{2}=2160 \mathrm{~kg}$ & $m_{4}=5040 \mathrm{~kg}$ \\
$\alpha=0 \mathrm{~s}$ & $k_{2}=364500 \mathrm{~N} / \mathrm{m}$ & $k_{4}=850500 \mathrm{~N} / \mathrm{m}$ \\
$\beta=0 s^{-1}$ & $d_{2}=4200 \mathrm{Ns} / \mathrm{m}$ & $d_{4}=9800 \mathrm{Ns} / \mathrm{m}$ \\
$g=9.8 \mathrm{~m} / \mathrm{s}^{2}$ & $v_{2}=6.9444 \mathrm{~m} / \mathrm{s}$ & $v_{4}=6.9444 \mathrm{~m} / \mathrm{s}$ \\
$n=4 ;$ & $y_{2}=6.5 \mathrm{~m}$ & $y_{4}=6.5 \mathrm{~m}$ \\
$m=4 ;$ & $\tau_{2}=0 . s$ & $\tau_{4}=0.49 \mathrm{~s}$ \\
& $G_{2}=0 \mathrm{~N}$ & $G_{4}=0 \mathrm{~N}$ \\
\hline
\end{tabular}

The data used for calculating this model are given in table 1. Computational results are presented in Figs. 4 - 11. 


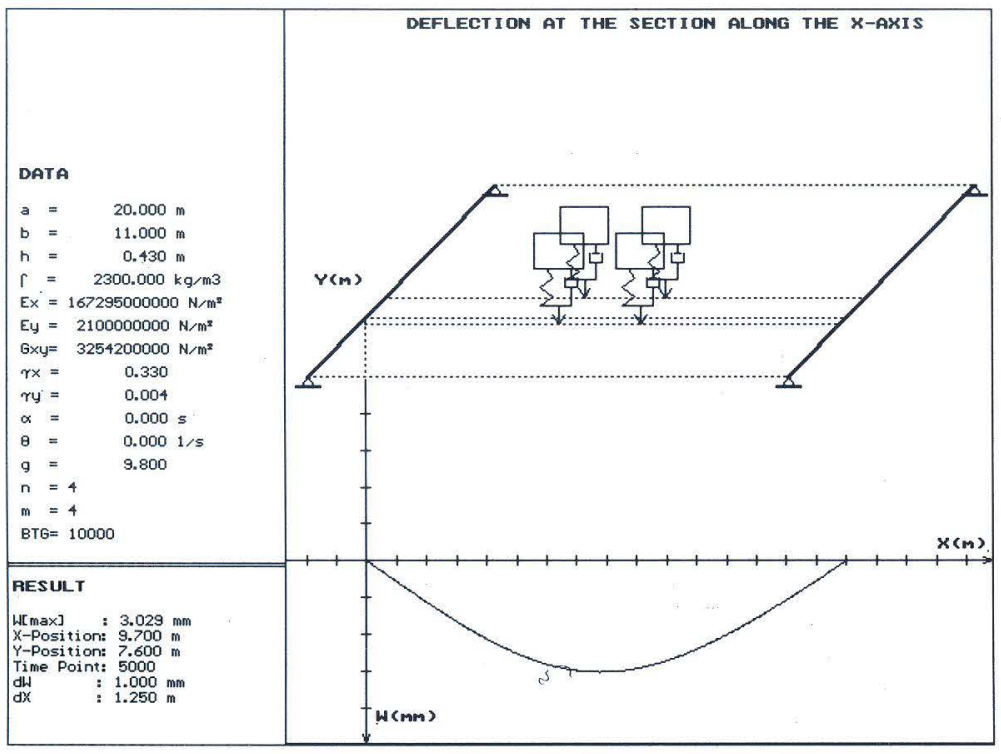

Fig. 4. Deflection at a section along the $x$ - axis $(y=7.6 \mathrm{~m}$, at $t=0.186 \mathrm{~s})$

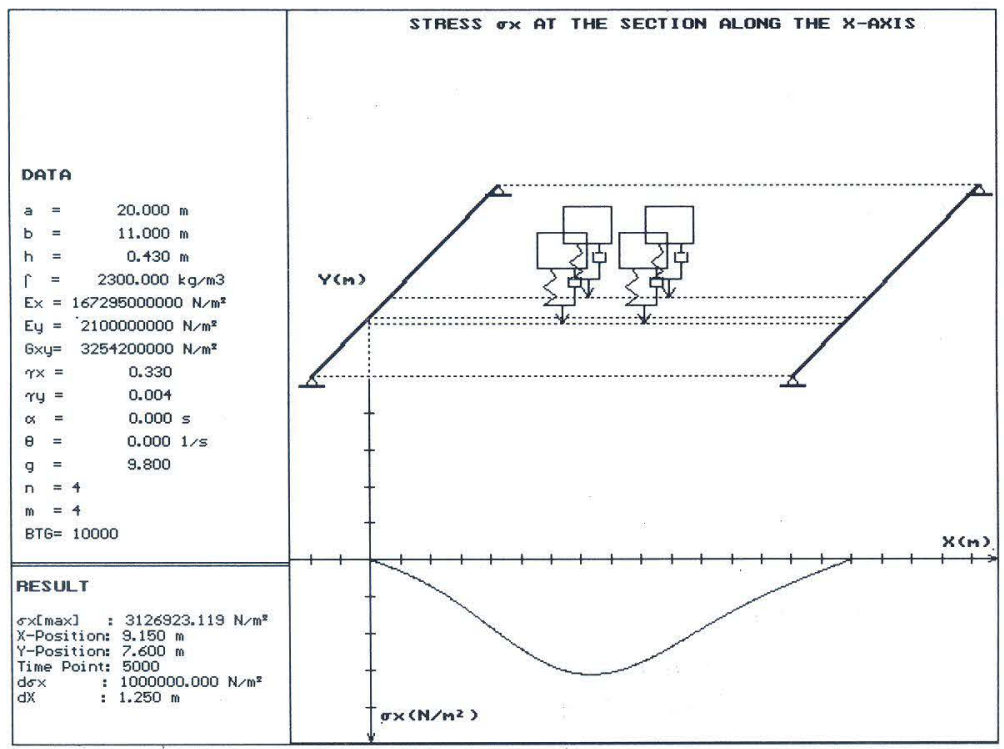

Fig. 5. Stress $\sigma_{x}$ at a section along the $x$ - axis $(y=7.6 \mathrm{~m}$, at $t=0.186 \mathrm{~s})$

\section{CONCLUSIONS}

In this article, the transverse vibration of orthotropic rectangular plates under the action of moving bodies is addressed. The following concluding remarks have been reached. 


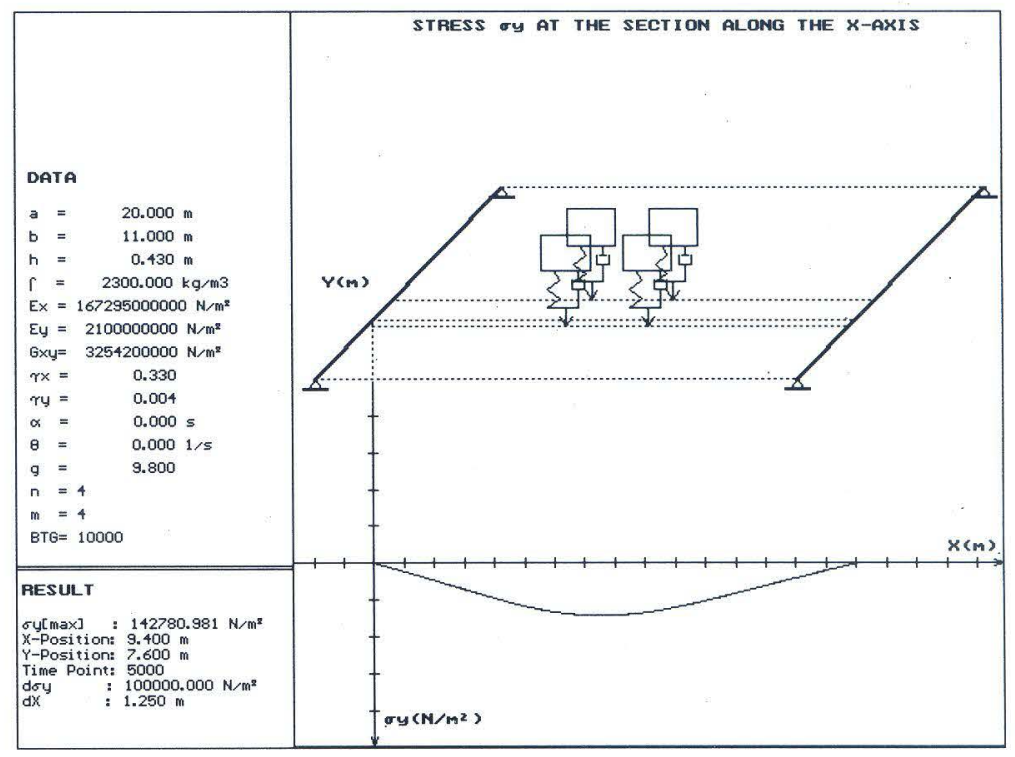

Fig. 6. Stress $\sigma_{y}$ at a section along the $\mathrm{x}-$ axis $(\mathrm{y}=7.6 \mathrm{~m}$, at $\mathrm{t}=0.186 \mathrm{~s})$

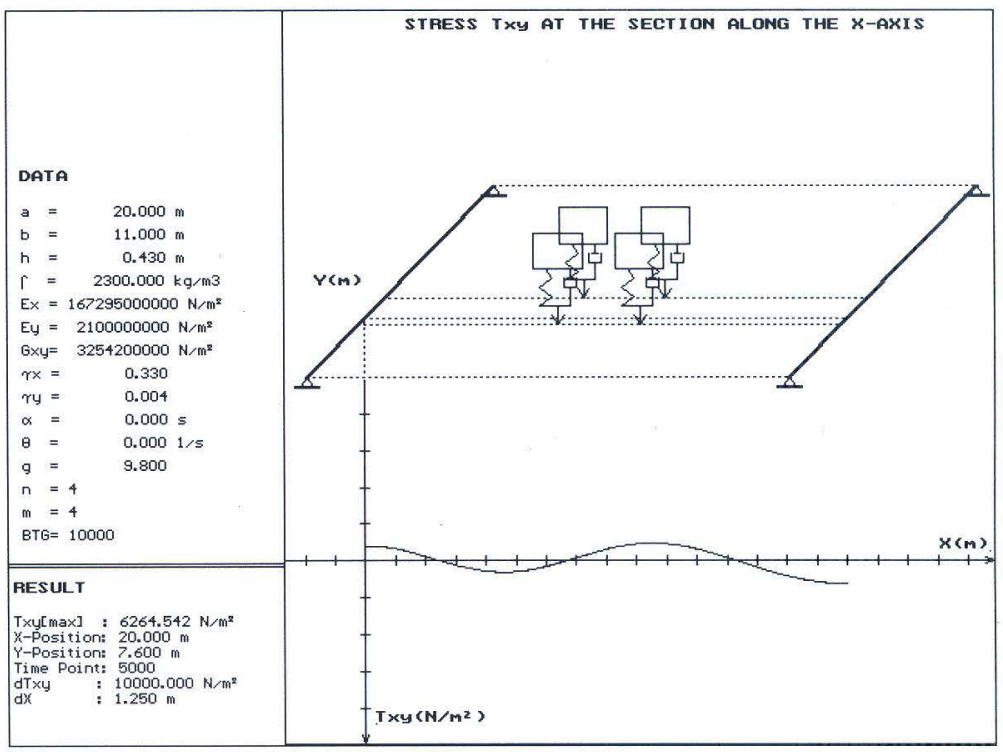

Fig. 7. Stress $\tau_{x y}$ at a section along the $x$ - axis $(y=7.6 \mathrm{~m}$, at $t=0.186 \mathrm{~s})$

The system of a partial differential equation and ordinary differential equations which describes the transverse vibration of orthotropic rectangular plate under moving bodies is established by the method of substructures.

The dynamic response of an orthotropic rectangular plate under the action of moving bodies has been investigated, both analytically and numerically. 


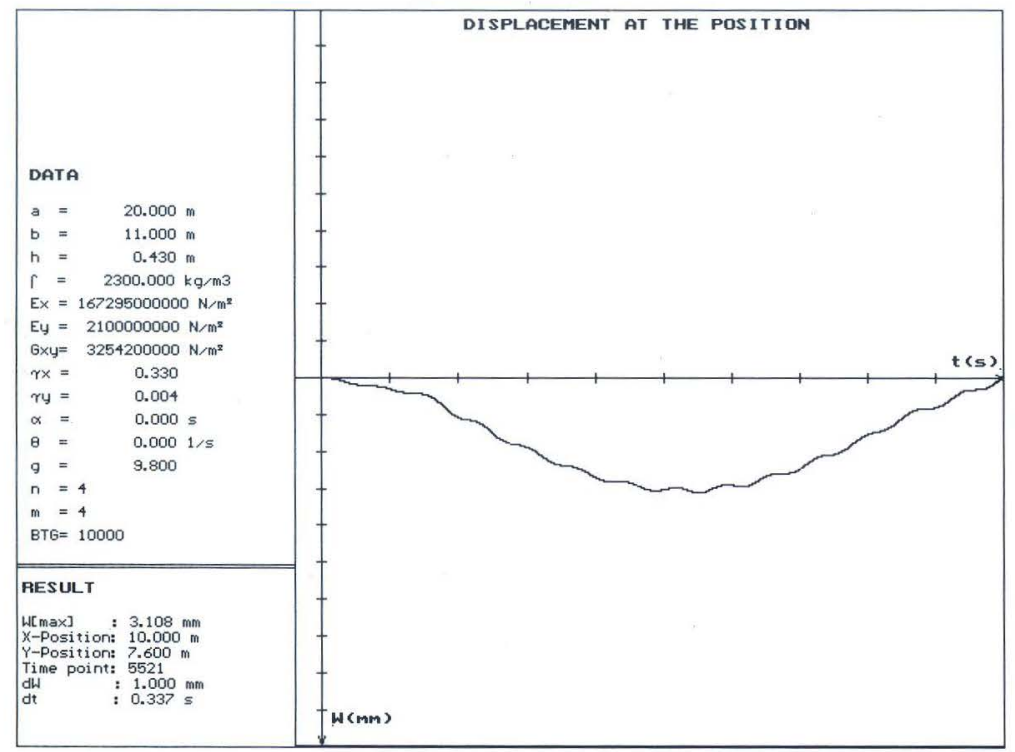

Fig. 8. Displacement at the position $x=10 \mathrm{~m}, y=7.6 \mathrm{~m}$

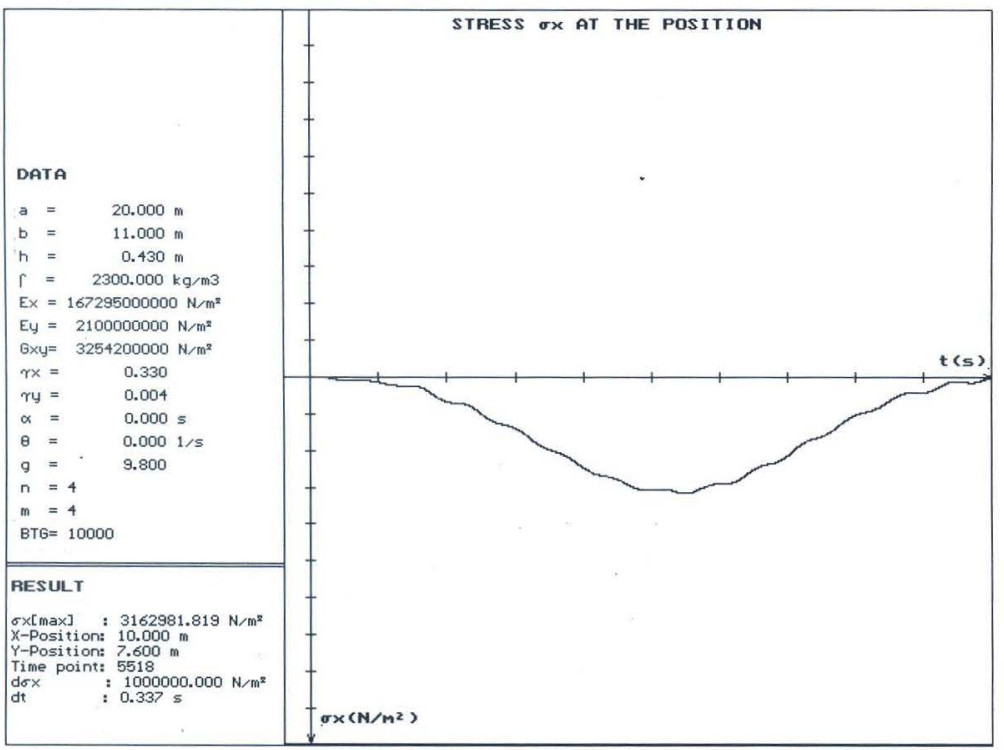

Fig. 9. Stress $\sigma_{x}$ at the position $x=10 \mathrm{~m}, y=7.6 \mathrm{~m}$

An algorithm and a computer program for the numerical calculation of transverse vibrations of orthotropic rectangular plates under moving bodies have been developed using $C^{++}$language. 


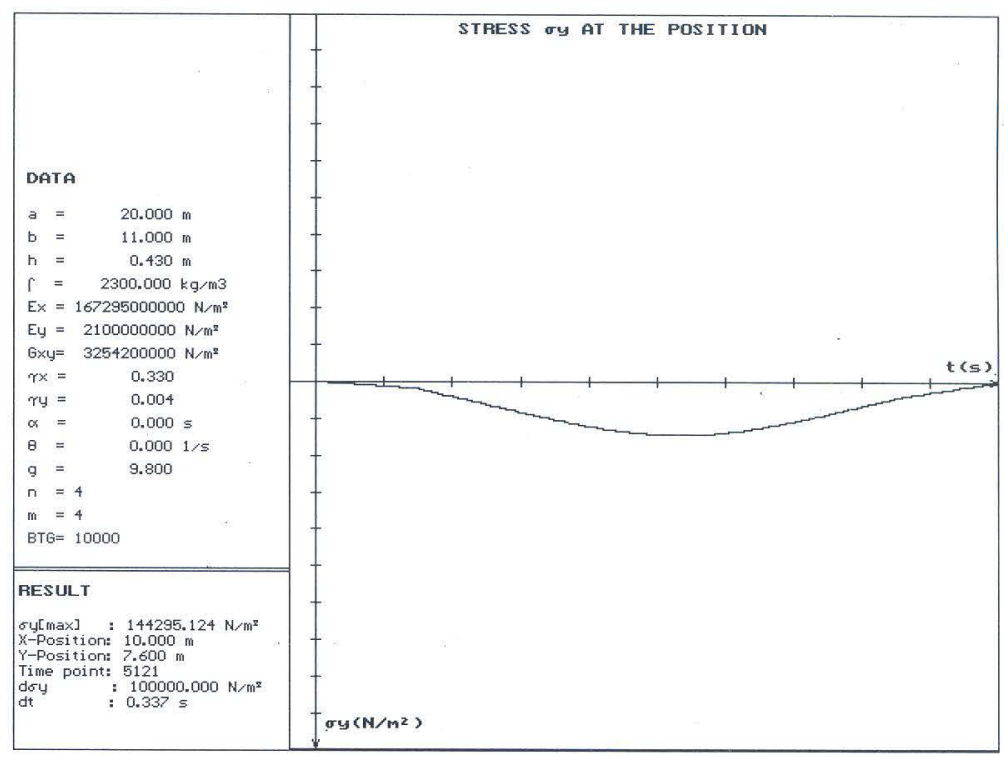

Fig. 10. Stress $\sigma_{y}$ at the position $x=10 \mathrm{~m}, y=7.6 \mathrm{~m}$

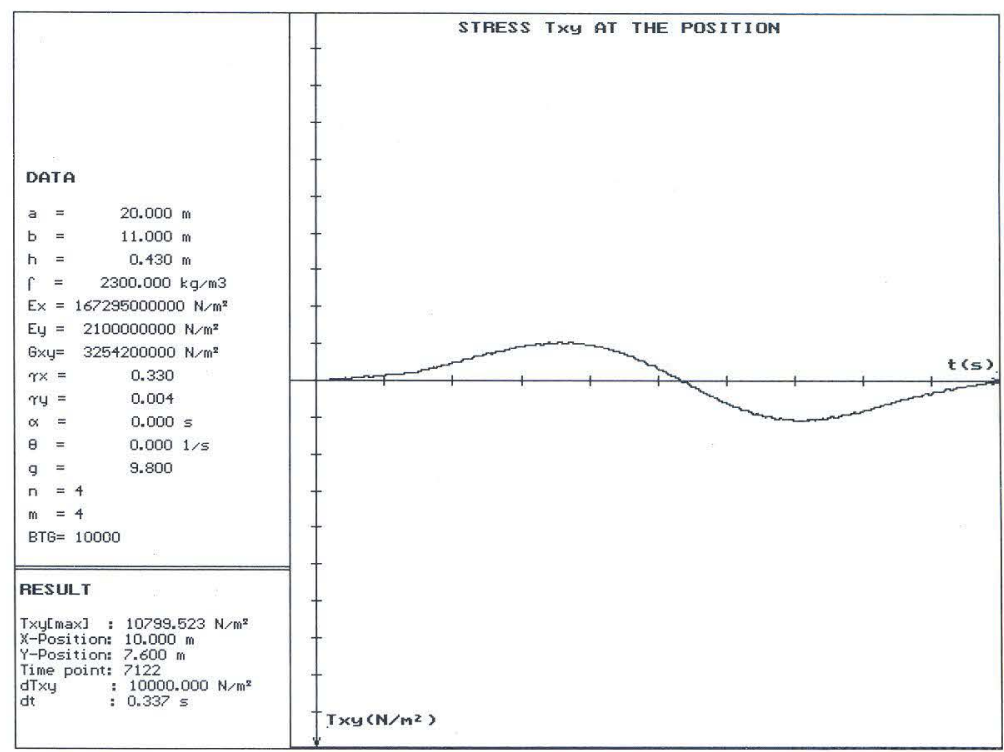

Fig. 11. Stress $\tau_{x y}$ at the position $x=10 \mathrm{~m}, y=7.6 \mathrm{~m}$

\section{ACKNOWLEDGMENT}

This paper was completed with the financial support of the German Research Foundation (DFG) and the National Foundation for Science and Technology Development of Vietnam. 


\section{REFERENCES}

[1] A. W. Leissa, Vibration of plates, National Aeronautics and Space Administration, Washington 1969.

[2] J. Wauer, Kontinuumsschwingungen, Vieweg+Teubner, Wiesbaden 2008.

[3] S. R. Soni, C. L. A. Rao, Vibration of orthotropic rectangular plates under in plane forces, Computer 85 structures 4 (1974) 1105 - 1115, Pergamon Press.

[4] A. N. Bercin, Analysis of orthotropic plate structures by the direct - dynamic stiffness method, Mechanics Research Communications 22 (5) (1995) 461 - 466.

[5] X. Q. Zhu, S. S. Law, Identification of moving loads on an orthotropic plate, Journal of Vibration and Acoustics 123 (2001) 283-244.

[6] S. Hurlebaus, L. Gaul, An exact series solution for calculations the eigen- frequencies of orthotropic plates with completely free boundary, Journal of Sound and Vibration 224 (2001) (5) 747-759.

[7] X. Q. Zhu, S. S. Law, Dynamic behaviour of orthotropic rectangular plates under moving loads, Journal of Engineering Mechanics 129 (2003) 79-87.

[8] F. T. K. Au, M. F. Wang, Sound radiation from forced vibration of rectangular orthotropic plates under moving loads, Journal of Sound and Vibration 289 (2005) 1057-1075.

[9] M. E. Biancolini, C. Brutti, L. Reccia, Approximate solution for free vibrations of thin orthotropic rectangular plates, Journal of Sound and Vibration 288 (2005) 321-344.

[10] Nguyen Van Khang, Nguyen Minh Phuong, Transverse vibrations of a continuous beam on rigid and elastic supports under the action of moving bodies, Technische Mechanik, Magdeburg 2002, Band 22, Heft 4, pp. 306-316.

[11] Nguyen Van Khang, Nguyen Phong Dien, Nguyen Thi Van Huong, Transverse vibrations of prestressed beams on rigid supports under the action of moving bodies, Archive of Applied Mechanics, Springer 2008 (accepted for publication).

[12] Nguyen Minh Phuong, Calculating transverse vibrations of a continuous beam and transverse vibrations of an orthotropic rectangular plate under the action of moving bodies (in Vietnamese), PhD Thesis, Hanoi University of Technology, 2008.

Received May 14, 2009

\section{DAO ĐộNG UỐN CƯA TẤM TRỰC HƯớNG HÌNH CHỮ NHẬT DƯớI TÁC DỤNG CỦA NHIỀU VẬT THỂ DI ĐộNG}

Các tấm trực hướng được sử dụng nhiều trong các ngành xây dựng, cầu đường, hàng không và hàng hải. Trong bài báo này trình bầy các kết quả nghiên cứu về dao động uốn của tấm trực hướng hình chữ nhật dưới tác dụng của nhiều vật thể di động trên tấm. Phương pháp tách cấu trúc được sử dụng để thiết lập các phương trình mô tả dao động uốn của tấm trực hướng hình chữ nhật dưới các vật thể di động. Sau đó phương pháp Ritz và phương pháp tích phân số được sử dụng để tính toán các đáp ứng động lực. 